\title{
Digital Technologies Preconditions in Traffic Management and Passengers' Fare Collection on Commuter Trains
}

\author{
Viktor Sankov \\ Department "Economics of labour and industrial \\ complexes" \\ Yuri Gagarin State Technical University of Saratov \\ Saratov, Russian Federation \\ sankovvg@mail.ru
}

\author{
Sergey Morozov \\ Department "Economics of labour and industrial \\ complexes" \\ Yuri Gagarin State Technical University of Saratov \\ Saratov, Russian Federation \\ morozovsa@sstu.ru
}

\author{
Mikhail Bochkarev \\ Department "Economics of labour and industrial complexes" \\ Yuri Gagarin State Technical University of Saratov \\ Saratov, Russian Federation \\ bochkarevmv@mail.ru
}

\begin{abstract}
The relevance ensuring collection of transportation fares from passengers in full by Suburban Passenger Companies (SPC) is an especially important aspect of their operation as it forms the companies' income in its fullness from their main activity. It can be effective only on the assumption of comprehensive integrated interaction of passenger flows and inspecting-cashing apparatus. As the functioning of passenger flows has a random, uncontrollable nature, it is the primary, determining element in the system to be served and submits a dynamic demand for generating an adequate reactive inspectingcashing impact on the flow, by the criterion of completeness of revenue collection - that is, ensuring the required quality of their service in aspect of the revenue collection. The research methods were the author's developed complex of models for constructing particular models necessary for the effective solution of individual tasks of managing the process of inspecting-cashing management on suburban passenger transportation. The result of the study is the theoretical justification for solving the company's internal target - to achieve the most complete collection of passenger transportation fees according to the criterion for the company in the form of a minimum amount of costs for the maintenance and operation of the service and losses on unearned income for the transportation of passengers.
\end{abstract}

Keywords: fare collection, transportation, commuter train, analytics, passenger traffic

\section{INTRODUCTION}

Modern systems of commuter passenger transportation services operate on a cyclical basis - with daily repetition of frequency dynamic characteristics, according to stable schedules of electric trains on routes. Passenger flows are, to a certain extent, "deformed" in time characteristics according to the timetables of electric trains following routes. But at the same time, daily passenger flows on routes have random fluctuations in their absolute characteristics, i.e. in size, thereby confirming the random nature of their formation, and at the same time the random nature of functioning with statistically regular dynamics of mathematical expectation and dispersion at the same intervals of day.

In accordance with the trains' schedule, daily commuter passenger transportation services are carried out along the existing routes of the transport hub. The transportation is preceded by preparation in the form of operational planning of all the processes carried out in a coordinated interaction of participants serving commuter transportation of passengers: crews of locomotive drivers, teams of inspectors-cashiers, security escorts. These groups of workers perform different functions in carrying out passenger transportation: locomotive drivers are responsible for observing the schedule of the electric train and its safety in accordance with the instructions of railroad regulation workers on the route; inspecting-cashing teams are responsible for the timely service of passengers in the form of identifying the availability of travel documents and selling tickets, if passengers do not have them; security escorts of inspectors-cashiers are responsible for their safety and the safety of proceeds from the sale of tickets. In exceptional cases, with a high occupancy of train cars and safety threats to the passengers and the train, it is possible to 
hubs are opened only on the basis of modern digital technologies for processing all operational information in the inspecting-and-cashing subsystem and maintaining its information platform at every moment and at each level in adequate informational condition $[10,11,12]$. The creation of a technical and technological complex for the total provision of a multitude of information-generating points of a geographically dispersed fare collection system also involves their continuous technological interaction in informationexchange activities, determined by the totality of the tasks to be solved and their information support in the required time frame of the daily iterative cycle.

If the set of tasks characterizes the completeness of the list of constructive coverage of the solution tasks in the list of iterative daily procedures, then integrating it with a system of automatic information collection and communicating the results of the solution to the performers in the activities in operation units forms a system of an automated cycle for implementing the iterative operation process on a high-quality information basis.

System management, on the principle of continuous approximation of its functioning to the optimum, is based on the inclusion to the software complex the tasks for continuous monitoring of the state of the managed system, and keeping it in the optimal region of the optimum criterion.

The replacement of the list of management actions of the completed operational cycle to the next one, i.e. to the list of actions on the next day, is provided by a system algorithm, which, along with the new information, also uses reports on the results of the previous day. This allows the management system to take into account and use information about changes that occurred in it at the previous operation cycle, in decisions to be implemented at the next management cycle. So in this logistics system the principle of adaptability to changes, both in the system itself and in the external environment, is implemented.

\section{RESULTS}

The addition to the system with a complex of analytical tasks makes the control part tuned to the solution of improvement and development tasks as well, i.e. selfoptimizing and improving in the direction of ensuring the highest possible collection of revenue when servicing passengers on commuter rail transportation. What is also important is the presence in the suburban passenger service system of two types of service devices - stationary and mobile - for selling and purchasing the tickets, due to which an operational justification of the reasonability of such service is possible, with regard to each stationary point on the route. The relatively small flows of passengers at many little-busy stations today do not justify the maintenance of stationary ticket offices: their running costs exceed the proceeds from the sale of tickets.

Thus, the transfer of the management of commuter passenger transportation within the powers of the suburban regional companies to the level of integrated problem solving in the connected areas of activity of the main functional structures is the today's problem of improvement. Considering and cashing services of suburban passenger companies on the network of commuter passenger transportation in transport 
the above-mentioned points in the program and statistical interaction of information related to the management of the process of commuter passenger traffic, let us present a systematic connection of information support with the basic functions of managing all elements of the process of commuter passenger transportation.

In accordance with the existing concept of the functional composition of controls [13], it can be schematically represented as following:

1) All information is collected and stored in a single place, structured according to the directions of the operation processes of the system.

2) The management objects are the operation processes: coordination of demand for commuter transportation of passengers with the work schedule of electric trains (marketing complex of tasks); collection of fare for the transportation of passengers (operational unit of ensuring the collection of passengers' fares); providing electric trains for passenger transportation on route (operational and dispatching support for the transportation process).

3) Coordination of the demand for commuter passenger transportation with the schedule of electric trains (marketing complex of tasks) is a set of tasks for studying the demand for transportation formed by the structure of passenger flows [8, 16 ] based on targeted travel of passengers, and the development of schedules of electric trains that are adequate (fully satisfying) the needs of the main categories of passengers on trips.

4) Passenger transportation fare collection (operational unit of ensuring the collection passengers' fares) is the largest unit in terms of the number of employees. The service solves the problem of ensuring the full collection of fare from the passengers travelling with suburban trains. The effective activity of this service is ensured by solving a set of economic and statistical tasks that monitor the process, analyze its economic assessment and constantly improve it by continuous search for and implementation of effective measures.

5) Provision of the electric trains for passenger transportation on route (operational and dispatching support for the transportation process). The unit is responsible for transport support, i.e. the supply of electric trains to routes in accordance with the current schedule.

\section{DISCUSSION}

The marketing and operational-dispatching activities of suburban passenger companies are working to achieve the main goal - satisfying the transport needs of the population of suburban area for transportation. At the same time, as shown above, they each implement their own tasks, agreed within the framework of the target orientation of the entire system.

The fare collection service, although it interacts with a client - an external consumer of services, - solves the internal target of the company - to achieve the most complete collection of passenger transportation fees according to the criterion for the company in the form of a minimum amount of costs for the maintenance and operation of the service and losses on unearned income for the transportation of passengers.

\section{CONCLUSION}

The determining information for all processes is data about the passenger flows served by the company and the proceeds from the servicing of these flows. Processes are repeated every day, forming this information. However, the element of randomness introduced by the nature of the formation of these flows makes it necessary, by using and accumulating these data, to refine and develop the methods for predicting, planning, organizing, controlling, analyzing and regulating the functioning of the "suburban passenger transportation company" system, improve them and look for ways to increase the effectiveness of its work.

A very positive point is that the collection of information on the served passenger flows through their migration lines between stations and on the cash flows of receipts from them is already quite well established. It allows you to quickly build an objective picture of their values and dynamics over shortand long-time horizons, measure all the characteristics of interest and solve all problems in the whole complex of processes of the company's functioning in an interconnected form. All this is effectively solved on a single digital platform [14]. Of course, the solution of all the tasks of the existing services in the company requires large amounts of information of state, macroeconomic, regional, sectoral and private levels in terms of the use of elements of its operational subsystems. However, hierarchical databases and rational exchange technologies between them simplify the solution of the problems at the level of individual enterprises, which improves the management process, increasing its effectiveness $[15,16]$. The current state of information support for the management of suburban passenger companies is moving in the direction of increasing information links, providing ever greater information sufficiency, close to an integrated, allinclusive, systematic reflection of the necessary characteristics, their dynamics, reliable analysis of situations, perfect forecasting and valid planning for solving short-, medium- and long-term tasks of integrated system functioning and development.

\section{REFERENCES}

[1] A.A. Ali, J. Eliasson, J. Warg, "Measuring the Socio-economic Benefits of Train Timetables Application to Commuter Train Services in Stockholm", Transportation Research Procedia, vol. 27, 2017, pp. 849856, doi: 10.1016/j.trpro.2017.12.124.

[2] P. Gurník, "Next Generation Train Control (NGTC): More Effective Railways through the Convergence of Main-line and Urban Train Control Systems", Transportation Research Procedia, vol. 14, 2016, pp. 1855-1864. doi:10.1109/TITS.2018.2806187.

[3] I.A. Sil'chenkov, "Suburban rail transport: transportation organization and tariff policy [Prigorodnyj zheleznodorozhnyj transport: organizaciya perevozok i tarifnaya politika]", Transport Rossijskoj Federacii, vol. 6(37), 2011, (in Russian, of 2019/10/15).

[4] Y. Xu, B. Jia, A. Ghiasi, X. Li, "Train routing and timetabling problem for heterogeneous train traffic with switchable scheduling rules", Transportation Research Part C: Emerging Technologies, vol. 84, 2017, pp. 196-218. doi: 10.1016/j.trc.2017.08.010. 
[11] D.V. Glazkov, "Calculation of the number and destination of trains in long-distance and local traffic, depending on the structure of passenger traffic" - URL: http://tekhnosfera.com/raschet-chisla-i-naznacheniypoezdov-v-dalnem-i-mestnom-soobschenii-v-zavisimosti-ot-strukturypassazhiropotoka (in Russian, of 2019/10/15).

[6] R. Chebotarev, A. Garanichevsky, "From quantity to quality: Data analytics and increasing of passenger transportation efficiency", CROC. - URL: https://www.osp.ru/netcat_files/18/10/chebotarev_garanichev.PDF (in Russian, of 2019/10/15).

[7] Who and in what case can fine a fare-beater on a bus and electric train. URL: http://inpavposad.ru/novosti/eto-interesno/kto-i-v-kakom-sluchaemozhet-oshtrafovat-bezbiletnika-v-avtobuse-i-elektrichke (in Russian, of 2019/10/15)

[8] X. Bouleta, M. Zargayounabd, F. Leurentcd, B. Kabalanc, F. Ksontinia, "A Dynamic Multiagent Simulation of Mobility in a Train Station", Transportation Research Procedia, vol. 27, 2017, pp. 744-751, doi: 10.1016/j.trpro.2017.12.100.

[9] R.B. Ellison, A.B. Ellison, S.P. Greaves, B. Sampaio, "Electronic ticketing systems as a mechanism for travel behaviour change? Evidence from Sydney's Opal card", Transportation Research Part A: Policy and Practice, vol. 99, 2017, pp. 80-93, doi: 10.1016/j.tra.2017.03.004.

[10] S. Gestreliusa, M. Aronssona, A. Petersonb, "A MILP-based heuristic for a commercial train timetabling problem", Transportation Research Procedia, vol. 27, 2017, pp. 569-576, doi: 10.1016/j.trpro.2017.12.118.

[12] L. Zhang, Y. Qin, X. Meng, L. Wang, T. Zhu, "MPSO-Based Model of Train Operation Adjustment", Procedia Engineering, vol. 137, 2016, pp. 114-123, doi: https://doi.org/10.3390/en12132518.

[13] V.G. Sankov, S.A. Morozov, "Incomplete passenger fare at commuter train", 2018 International Multi-Conference on Industrial Engineering and Modern Technologies, FarEastCon 2018, p. 1398, doi:10.1007/9783-030-18553-4_96.

[14] Departmental target program of the Ministry of Transport of the Russian Federation "Digital Platform of the Transport Complex of the Russian Federation" / Ministry of Transport of the Russian Federation. - URL: https://www.mintrans.ru/documents/8/10143 (in Russian, of 2019/10/15)

[15] Collection of sociological data using database technologies. Creation of database tables and forms. - URL: http://bukvi.ru/computer/sbordannyx-sociologicheskogo-xaraktera-s-ispolzovaniem-texnologij-bazdannyx-sozdanie-tablic-i-form-bd.html (in Russian, of 2019/10/15)

[16] T. Robenek, S.S. Azadeh, Y. Maknoon, M. Lapparent, M. Bierlaire, "Train timetable design under elastic passenger demand", Transportation Research Part B: Methodological, vol. 111, 2018, pp. 19-38, doi: 10.1016/j.trb.2018.03.002. 